\title{
Commentary: Portable, normothermic ex vivo lung perfusion-High hopes, not yet fully realized
}

Jeffrey Javidfar, MD

\author{
From the Division of Cardiothoracic Surgery, Emory University School of Medicine, Atlanta, Ga. \\ Disclosures: Author has nothing to disclose with regard to commercial support. \\ Received for publication March 11, 2019; accepted for publication March 11, 2019; available ahead of print April \\ $17,2019$. \\ Address for reprints: Jeffrey Javidfar, MD, Division of Cardiothoracic Surgery, Emory University School of Med- \\ icine, 1365 Clifton Rd NE, Clinic Building A, Room 2219, Atlanta, GA 30322 (E-mail: jjavidfarmd@ gmail. \\ com) \\ J Thorac Cardiovasc Surg 2019;158:1264-5 \\ $0022-5223 / \$ 36.00$ \\ Copyright (c) 2019 by The American Association for Thoracic Surgery \\ https://doi.org/10.1016/j.jtcvs.2019.03.044
}

The standard of care in donor lung preservation has changed little since the late 1990s. Large volumes of lowpotassium dextran-glucose solution are flushed through the lung, which is then packed and shipped on ice. The donor lung is exposed to ischemia-reperfusion injury and is associated with a $30 \%$ primary graft dysfunction (PGD) rate at 72 hours, which correlates with increases in chronic lung allograft dysfunction. ${ }^{1,2}$

Ex vivo lung perfusion (EVLP) represents a leap forward in donor lung preservation. Its potential advantages include an expanded donor pool, lower PGD rates, and improved transplant survival rates. The Organ Care System Lung (OCS Lung; Transmedics, Andover, Mass) is a bloodbased, normothermic portable EVLP system. After standard preservation, the explanted lung is connected to the device in the donor operating room. The proprietary OCS lung solution is combined with packed red blood cells and then pumped through the circuit as the lung is rewarmed to $37^{\circ} \mathrm{C}$. The ischemic times are reduced, and acute lung injury is mitigated.

In this issue of the Journal, Loor and colleagues ${ }^{3}$ cite the International Randomized Study of the TransMedics Organ Care System for Lung Preservation and Transplantation (INSPIRE) trial $^{4}$ to argue that the OCS Lung can be used safely to preserve and transport donor lungs meeting standard criteria over greater distances with longer total crossclamp times. This expands a high-volume EVLP center's donor pool and decreases wait list times. OCS Lung may be particularly useful for recipients with high pretransplant panel reactive antibodies, for whom immunologically compatible donors are harder to find.

The OCS and standard of care arms of the INSPIRE trial have similar safety, efficacy, and survival profiles. The OCS cohort has significantly reduced cold ischemic times ( $>2$ hours), decreasing peak airway pressures and vascular resistance, and a higher final $\mathrm{PaO}_{2}$ to inspired oxygen fraction ratio. There are also promising clinical trends,

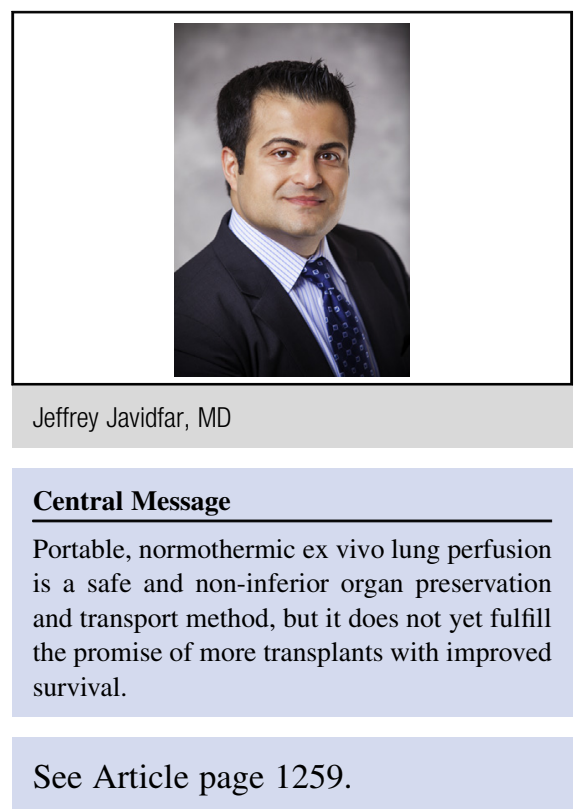

including a significant decrease in PGD grade 3 at less than 72 hours. There was no difference, however, in PGD grade 3 at 72 hours-the interval that correlates most with chronic lung allograft dysfunction. ${ }^{4}$

Is the expansion of a center's donor pool and transient improvement in PGD - without any other statistically significant clinical markers-sufficient to offset the risk and considerable expense of adding another variable to the already complex transplant process? Loor and colleagues ${ }^{3}$ answer this fundamental question affirmatively.

This enthusiasm should be tempered by the INSPIRE trial's acknowledged limitations. The overall donor pool is not expanded. There is no survival benefit. Nor is there a significant difference in ventilation times, intensive care unit length of stay, or hospital length of stay. ${ }^{4}$ Absent such clinical benefits, the data may not support potential costs savings. Moreover, the total transplant expenses are higher-not only OCS Lung costs, but also personnel and travel expenses for longer distances. ${ }^{3}$ Without thoughtful public planning, OCS Lung could create an organ-sharing model that disadvantages recipients unable to reach a high-volume EVLP center, as well as recipients from donor-rich regions whose organs could be reallocated.

By limiting ischemic times, OCS Lung breaks geographic barriers for standard donors in the INSPIRE 
trial, but the prospects of a larger donor pool with improved survival have yet to be fully realized. However, the ongoing expanded criteria OCS Lung trials offer the possibility of enlarging the total organ pool through the use of extended criteria donors. It is there that the greatest benefits of OCS may lie. ${ }^{5}$

\section{References}

1. Diamond JM, Lee JC, Kawut SM, Shah RJ, Localio AR, Bellamy SL, et al; Lung Transplant Outcomes Group. Clinical risk factors for primary graft dysfunction after lung transplantation. Am J Respir Crit Care Med. 2013;187:527-34.
2. Whitson BA, Prekker ME, Herrington CS, Whelan TP, Radosevich DM, Hertz M et al. Primary graft dysfunction and long-term pulmonary function after lung transplantation. J Heart Lung Transplant. 2007;26:1004-11.

3. Loor G, Parulekar A, Smith M. Evaluation of the INSPIRE trial and its implications for lung transplantation with normothermic portable ex vivo lung perfusion. J Thorac Cardiovasc Surg. 2019;158:1259-63.

4. Warnecke G, Van Raemdonck D, Smith MA, Massard G, Kukreja J, Rea F. Normothermic ex-vivo preservation with the portable Organ Care System Lung device for bilateral lung transplantation (INSPIRE): a randomized, open-label, noninferiority, phase 3 study. Lancet Respir Med. 2018;6:357-67. Erratum in: Lancet Respir Med. 2018;6:e27.

5. Loor G, Smith M, Kukreja J, Ardehali A, Moradiellos J, Varela A, et al. The OCS Lung EXPAND international trial interim results. J Heart Lung Transplant. 2016; 35(4 Suppl):S68-9. 